\title{
A preclinical study-systemic evaluation of safety on mesenchymal stem cells derived from human gingiva tissue
}

\author{
Jun Zhao ${ }^{1 \dagger}$, Julie Wang ${ }^{2+}$, Junlong Dang ${ }^{3+}$, Wangyu Zhu ${ }^{4}$, Yaqiong Chen ${ }^{5}$, Ximei Zhang ${ }^{2}$, Junliang Xie ${ }^{6}$, Bo Hu ${ }^{5}$, \\ Feng Huang ${ }^{1}$, Baoqing Sun ${ }^{7^{*}}$, Joseph A. Bellanti ${ }^{8}$ and Song Guo Zheng ${ }^{2^{*}}$ (D)
}

\begin{abstract}
Background: Mounting evidence has shown that a novel subset of mesenchymal stem cells (MSCs) derived from human gingiva referred to as gingival mesenchymal stem cells (GMSCs) displays a greater immunotherapeutic potential and regenerative repair expression than MSCs obtained from other tissues. However, the safety of the use of transplanted GMSCs in humans remains unclear.

Methods: In this study, we evaluated the safety of GMSCs transplanted into mouse, rat, rabbit, beagle dog, and monkey as well as two animal models of autoimmune diseases.

Results: In short- and long-term toxicity tests, infused GMSCs had no remarkable adverse effects on hematologic and biochemical indexes, particularly on the major organs such as heart, liver, spleen, and kidney in recipient animals. It was also shown that GMSCs were well tolerated in other assays including hemolysis, vascular, and muscular stimulation, as well as systemic anaphylaxis and passive skin Arthus reaction in animal models. GSMC infusion did not cause any notable side effects on animal models of either autoimmune arthritis or lupus.

Significantly, GMSCs most likely play no role in genotoxicity and tumorigenesis. The biological features remained stable for an extended period after cell transfer.

Conclusions: GMSCs are safe in various animal models of autoimmunity, even during active disease episodes, especially in monkeys. This study paves a solid road for future clinical trials of GMSCs in patients with autoimmune and inflammatory diseases.
\end{abstract}

Keywords: Gingival mesenchymal stem cells (GMSCs), Mesenchymal stromal cell, Safety

\section{Background}

Recently, mesenchymal stem cells (MSCs) have been considered as a promising therapeutic source for transplantation under various disease settings, especially autoimmune and inflammatory diseases, primarily for their anti-inflammatory and immune-modulatory properties [1-5]. Additionally, MSCs hold great potential for their ability to differentiate into many different tissues and

\footnotetext{
* Correspondence: sunbaoqing@vip.163.com; SongGuo.Zheng@osumc.edu ${ }^{\dagger} J u n$ Zhao, Julie Wang and Junlong Dang contributed equally to this work. ${ }^{7}$ Department of Allergy and Clinical Immunology, State Key Laboratory of Respiratory Disease, National Clinical Research Center of Respiratory Disease First Affiliated Hospital of Guangzhou Medical University, Guangzhou, China ${ }^{2}$ Division of Immunology and Rheumatology, Department of Internal Medicine, The Ohio State University College of Medicine, Columbus, USA Full list of author information is available at the end of the article
}

thus are capable of repairing many different damaged tissues [6]. Since the original description of their isolation from the bone marrow by Friedenstein et al. [7], multiple organs and tissues have been reported to be potential sources of MSCs, such as the cord blood [8], umbilical cord $[8,9]$, adipose tissue [10], amniotic membrane [11], placenta [12], tonsils [13], dental pulp [14], skin [15, 16], and fetal lung and liver [17].

In 2009, Angeles et al. [18] isolated a new population of stem cells from human gingiva, that were referred to as gingiva-derived mesenchymal stem cells (GMSCs), which exhibited clonogenicity, self-renewal, and multipotent differentiation capacities. This stem cell subset not only displayed superior properties of ease of harvesting and expansion in vitro, independency of growth

(c) The Author(s). 2019 Open Access This article is distributed under the terms of the Creative Commons Attribution 4.0 International License (http://creativecommons.org/licenses/by/4.0/), which permits unrestricted use, distribution, and 
factor and serum requirements, non-tumorigenicity [19], steady phenotype, and telomerase activity in long-term culture but also benefited from additional advantages in addressing ethical concerns of access compared with MSCs isolated from other sources. GMSCs display the same differentiation and regeneration properties with MSCs from other tissues. In vitro, single colony-derived GMSCs have been shown to differentiate into adipocytes and osteoblasts [18]. Using porcine small intestinal submucosa extracellular matrix (SIS-ECM) and human GMSCs as a GMSC/SIS-ECM tissue graft for the tongue reconstruction and the constructs accelerates wound healing and muscle regeneration and maintains the overall tongue shape [20]. In addition, based upon their known immunomodulatory properties, we have previously reported that adoptive transfer of GMSCs in a mouse model of rheumatoid arthritis not only significantly reduced the severity of the arthritis and downregulated the production of Th1 and Th17 inflammatory cytokines (i.e., interferon- $\gamma$ and interleukin-17A) but also enhanced Treg cell differentiation [3]. We also showed that GMSCs dramatically suppressed contact hypersensitivity by decreasing infiltration of dendritic cells, CD8+ $\mathrm{T}$ cells, Th17, and mast cells, as well as a reciprocal increased infiltration of Treg cells [21]. GMSCs co-cultured with macrophages have been shown to convert macrophages into the M2 anti-inflammatory phenotype $[6,22]$. In models of experimental colitis and diabetes, systemic infusion of GMSCs significantly ameliorated colonic inflammation, restored the injured gastrointestinal mucosal tissues, and decreased the levels of glucose as well as protected the pathology of the islet in mice [18]. Recently, Huang et al. have shown that GMSCs not only can suppress cell-mediated diseases but also were superior to bone marrow mesenchymal stem cells (BMSCs) in inhibiting xenogenic GVHD in humanized animal models [23, 24]. Collectively, these studies suggest that GMSCs may be a promising candidate for cell-based therapy of autoimmune and inflammatory diseases.

The safety of transplanted GMSCs is an important consideration in the clinical setting. Although, direct endomyocardial transplantation of MSCs has been shown to be safe [25], intravascular infusion may lead to occlusion in the distal microvasculature because of the large cell size [26]. Moreover, long-term transplantation of BMSCs was reported to promote tumor growth $[27,28]$ and did not achieve effective results for disease treatment [29]. Safety considerations for the therapeutic use of MSCs, therefore, appear to be the main constraint for the development of MSC-based therapy for a variety of human diseases. Until now, there have been no data available that address GMSC clinical safety. The purpose of the present study was to evaluate GMSC safety in various animal strains and models and to use these findings in support of their use in clinical trials.

\section{Methods}

\section{Cell culture}

Human GMSCs were isolated as described previously [18]. Briefly, gingival tissues were obtained from discarded tissues following tooth extraction procedures and were aseptically incubated overnight at $4{ }^{\circ} \mathrm{C}$ with dispase $\left(2 \mathrm{mg} / \mathrm{ml}\right.$, Sigma) and then digested at $37^{\circ} \mathrm{C}$ for $2 \mathrm{~h}$ with $4 \mathrm{mg} / \mathrm{ml}$ collagenase IV. The cell suspension was plated on dishes with complete $\alpha$-MEM (Invitrogen) containing 10\% FBS (Gibco), 1\% penicillin/streptomycin (Invitrogen), 1\% L-glutamine (Invitrogen), and 1\% nonessential amino acid (Invitrogen). GMSCs used in the experiments are all third passage with cell purity (CD29 and CD90 expression) at $\geq 95 \%$. Additionally, the differentiation ability of adipogenesis and osteogenesis must be positive and the test for the presence of bacteria, fungus, mycoplasma, hepatitis virus, and endotoxin must all be negative. All individuals provided informed consent for the use of their tissues in this study which was approved by the ethical committee of the Third Affiliated Hospital at the Sun Yat-sen University, China (2018-02-195-01).

\section{Vascular stimulation test}

This experiment is in order to determine whether any substance plays a role in stimulating blood vessels [30]. In this test, New Zealand white rabbits $(2.02-2.14 \mathrm{~kg})$ were infused with GMSCs at a dosage of $1.2 \times 10^{6} / \mathrm{kg}$ via the ear marginal vein and once daily for 2-4 days. A $0.9 \% \mathrm{NaCl}$ solution was used as a control. Any abnormal changes (such as bleeding, swelling, cyanochroia, or tissue necrosis) occurring in vascular and surrounding tissues were observed to evaluate the influence of GMSCs treatment. After $96 \mathrm{~h}$ of the last treatment, vascular and surrounding tissues were collected and fixed with $4 \%$ paraformaldehyde and paraffin sections were stained with hematoxylin and eosin (H\&E). The infiltration of inflammatory cells and integrity of tissue was analyzed to estimate the degree of vascular irritation.

\section{Muscle irritation test}

A modification of the local muscular tolerance study has been described previously [31]. Briefly, the assay consists of a single intramuscular injection of $1.0 \mathrm{ml}$ GMSC suspension into the right four-headed thigh muscle of rabbits at a concentration of $1.2 \times 10^{5}$ cells $/ \mathrm{ml}$. Saline was injected into the corresponding muscle of the left leg as a negative control. At 24 and $48 \mathrm{~h}$ after injection, any changes in stimulation such as congestion, edema, degeneration, or necrosis at the injection sites in the muscles were observed. The tissues at the sites of injection were collected and fixed with $4 \%$ paraformaldehyde, and paraffin sections were stained with H\&E. The infiltration of inflammatory cells and integrity of tissue was analyzed to estimate the degree of muscle irritation. 


\section{Hemolysis test}

To detect whether GMSCs could cause lysis of erythrocytes, a hemolytic test was conducted as previously reported [31]. Fresh blood was collected from a healthy rabbit to obtain an erythrocyte suspension. A $2 \%$ suspension $(2.5 \mathrm{ml})$ was added to $1.2 \times 10^{5} / \mathrm{ml}$ of GMSCs from $0.1-0.5 \mathrm{ml}$; meanwhile, $2.5 \mathrm{ml} 0.9 \% \mathrm{NaCl}$ solution and distilled water was respectively as negative and positive control. The mixed liquids were blended gently and incubated at $37^{\circ} \mathrm{C}$. Hemolysis (supernatant will be red and transparent) or erythrocyte sedimentation was observed at $0.25,0.5,0.75,1,2$, and $3 \mathrm{~h}$ after the addition of $2 \%$ suspension to GMSCs.

\section{Systemic anaphylaxis in beagles}

Anaphylaxis is a serious allergic reaction triggered by specific antigens that is rapid in onset and may be fatal [32]. In order to investigate the possible effects of GMSCs in systemic anaphylaxis, GMSCs were infused at a dosage of $2 \times 10^{6} / \mathrm{kg}$ (low-dose group) and $4 \times 10^{6} / \mathrm{kg}$ (high-dose group) through a forelimb vein, in order to sensitize the models every 2 days for three times. After 14 days of the experiment, a stimulating intravenous injection was applied with a twofold dose that used for sensitization $\left(4 \times 10^{6} / \mathrm{kg}\right.$ and $\left.8 \times 10^{6} / \mathrm{kg}\right)$. A similar volume of $0.9 \% \mathrm{NaCl}$ solution was used as a control. Changes in the behavior of dogs in each group were observed continuously before and after injection and scored according to the symptoms shown in Additional file 2: Table S1. Moreover, $2 \mathrm{ml}$ of venous blood was obtained from each dog before the first injection for sensitization, before stimulation, and $10 \mathrm{~min}$ after the stimulating injection (post stimulation). This blood was centrifuged at 3000 $\mathrm{rpm} / \mathrm{min}$ for $10 \mathrm{~min}$ at room temperature to detect the serum levels of histamine by ELISA kit (TSZ, USA).

\section{The passive skin Arthus reaction}

A passive Arthus reaction was performed as described before [33]. Rat antisera against GMSCs and BSA was prepared as follows: $3.0 \times 10^{6} / \mathrm{kg}$ (low dose) and $6.0 \times$ $10^{6} / \mathrm{kg}$ (high dose) of GMSCs and $100 \mathrm{mg} / \mathrm{kg}$ BSA were respectively mixed with complete Freund's complete adjuvant (1:1) to form emulsion that was subcutaneously injected three times into rats at two sites. GMSCs/BSA were emulsified in incomplete Freund's adjuvant. This emulsion was administered twice to rats. After 11 days, the serum was collected and was injected into the back of a recipient rat over a surface of about $3 \times 4 \mathrm{~cm}^{2}$ fur. The same dose of GMSCs, BSA, and 1\% Evans's blue solution was transferred intravenously into rats over a 40-h period. The skin of the Arthus lesion was excised for measurement of the amount of dye leakage after 30 min. A parallel experiment using $0.9 \% \mathrm{NaCl}$ solution was used to a negative control.

\section{Short-term and long-term toxicity test}

Short-term toxicity tests in rats were performed as follows: $6.0 \times 10^{7}$ and $1.2 \times 10^{8} / \mathrm{kg}$ of GMSCs was transplanted i.v. into rats, and $0.9 \% \mathrm{NaCl}$ solution was injected as a negative control. Weight, mortality, reactivity, and histopathological examination were conducted every $24 \mathrm{~h}$ for 21 days.

Long-term toxicity test was divided into four groups: (a) negative control $0.9 \% \mathrm{NaCl}$ solution, (b) low dose $7.5 \times 10^{6} / \mathrm{kg}$ of GMSCs, (c) middle dose $1.5 \times 10^{7} / \mathrm{kg}$ of GMSCs, and (d) high dose $3.0 \times 10^{7} / \mathrm{kg}$ GMSCs. Rats were treated via the tail vein once every 10 days over 30 days. Approximately $2 \mathrm{ml}$ of aortic abdominal blood of each rat was collected before treatment and at the first dose period (FP, 10 days after first dosing), at the withdrawal period (WP, 10 days after the third dosing) and at the recovery period (RP, 4 weeks after withdrawal). The following indices were measured: body weight, food consumption, ophthalmic test and urinalysis, hematological, and biochemical analysis. All blood samples were analyzed by automatic blood cell analyzer (BC-2800, Mindray).

\section{Toxicity test in autoimmune disease models}

The $100 \mu \mathrm{l}$ serum collected from $\mathrm{K} / \mathrm{BxN}$ mice, a spontaneous arthritis model, was injected i.p. into $\mathrm{C} 57 \mathrm{BL} / 6$ mice $(2 \times)$. These mice develop a standard $\mathrm{K} / \mathrm{BxN}$ serum transfer-induced arthritis (STIA) a few days after serum injection as previously reported [34].

A lupus model was established as in our previous report [35]. Briefly, C57BL/6 mouse bone marrow-derived dendritic cells (BMDCs) were prepared and incubated with activated syngeneic lymphocyte-derived DNA (ALD-DNA) for $12 \mathrm{~h}$ prior to injection. These cells were then transferred into $\mathrm{C} 57 \mathrm{BL} / 6$ mice that will gradually develop lupus syndromes.

$2.5 \times 10^{6}$ GMSCs/mouse (which are equivalent to 10-fold higher human clinical dose) were transferred respectively into STIA models via the tail vein and compared with $0.9 \% \mathrm{NaCl}$ solution. A similar procedure was conducted in the lupus model. Any abnormal reactions such as uneasiness, unsteady standing, or death in GMSC-treated models were observed and hematological and biochemical index was analyzed after 20 days (BC2800, Mindray).

\section{Salmonella typhimurium reverse mutation assay}

This assay is referred to as the "Ames test" that is used as an assay of genotoxicity [36, 37]. Briefly, $100 \mu \mathrm{l}$ of various concentrations of GMSCs $\left(3.2 \times 10^{3}, 1.6 \times 10^{4}\right.$, $8.0 \times 10^{4}, 4.0 \times 10^{5}$, and $2.0 \times 10^{6} /$ dish) was separately mixed with $100 \mu \mathrm{l}$ of $S$. typhimurium mutant strains TA97, TA98, TA102, TA100, and TA1535. Metabolic activity was assayed in the presence of $\mathrm{S} 9 \mathrm{mix}$, which consists of liver microsomal enzymes S9 (American 
MOLTOX Corporation), NADP $\mathrm{Na}_{2}, \mathrm{G}-6-\mathrm{P}-\mathrm{Na}, \mathrm{KCl}$, $\mathrm{MgCl}_{2}$, and PBS. These were added to the top agar and sequentially poured into minimal glucose agar plates that were inverted and placed in the dark at $37^{\circ} \mathrm{C}$ for 48 $\mathrm{h}$ and enumerated for the number of reverse colonies of S. typhimurium to determine mutagenesis and genotoxicity of GMSCs. $0.9 \% \mathrm{NaCl}$ solution was used as a negative control. For positive controls, $50 \mu \mathrm{g} / \mathrm{dish}$ dexon (Sigma) was used to treat TA97, TA98, and TA102 strains, and $2.0 \mu \mathrm{g} / \mathrm{dish} \mathrm{NaN} 3$ (Sigma) was used to treat TA100 and TA1535 strains in non-metabolic activity, while in metabolic activity, TA97, TA98, TA100, and TA102 strains were treated with $20 \mu \mathrm{g} /$ dish 2 -aminofluorene (2-AF, Sigma) and TA1535 was treated with $200 \mu \mathrm{g} / \mathrm{dish}$ cyclophosphamide (CP, Sigma).

\section{Chromosomal aberration assay}

In this experiment, Chinese hamster lung fibroblast cell line (CHL), a concentration of $1 \times 10^{6}$ cells/well, was pre-inoculated in a 6-well plate at $37^{\circ} \mathrm{C}$. After $48 \mathrm{~h}$, $2.5 \times 10^{4}, 5.0 \times 10^{4}$, or $1.0 \times 10^{5}$ of GMSCs was added to the plate and co-cultured in this system. After $6 \mathrm{~h}$, RPMI-1640 complete medium was added to the co-culture system and incubated continuously for $20 \mathrm{~h}$. After this incubation, the system was treated with $0.1 \mathrm{ml}$ colchicine (Sigma, $10 \mu \mathrm{g} / \mathrm{ml}$ ) for $4 \mathrm{~h}$ and cells were fixed with methanol, acetic acid (3:1), and stained by Giemsa dye for analysis. As a positive control, $0.1 \mathrm{ml}$ mitomycin $\mathrm{C}$ (Sigma) in non-metabolic activation and $0.1 \mathrm{ml} \mathrm{CP}$ in metabolic activation (presence of $0.5 \mathrm{ml} \mathrm{10 \%} \mathrm{S9} \mathrm{mix)}$ was utilized and $0.9 \% \mathrm{NaCl}$ solution was used as a negative control [38, 39].

\section{CM-Dil labeling technique}

CM-DI (Life Technologies, $4 \mu \mathrm{g} / \mathrm{ml}$ ) was applied to treated GMSCs $\left(2.0 \times 10^{7} / \mathrm{ml}\right)$ and incubated at $37^{\circ} \mathrm{C}$ for $30 \mathrm{~min}$. Afterward, GMSCs were washed with PBS and finally dispersed in $0.9 \% \mathrm{NaCl}$ solution. CM-DI-treated GMSCs $\left(7.5 \times 10^{6} / \mathrm{kg}\right)$ were transferred into rats through tail vein, with $0.9 \% \mathrm{NaCl}$ solution injection serving as negative control. On 10, 30, and 58 days, frozen-section samples of the heart, liver, lung, spleen, kidney, brain, thymus, and muscle were prepared, and the distribution and homing of GMSCs in these organs were observed using the fluorescence microscopy (Nikon 80i).

Furthermore, the Cell Tracker Red CMTPX dye (Thermo Fisher Scientific)-labeled GMSCs were infused into C57BL/6 mice. Labeled GMSCs were monitored and sorted for biomarkers (CD90, CD105, CD39, CD73, CD44, HLA-ABC, HLA-DR) by flow cytometry (FACS) on days 1,2 , and 4. To examine the suppressive effect of isolated GMSCs, GMSCs were added to T cells labeled with carboxyfluorescein succinimidyl ester (CFSE, BioLegend) and stimulated with muromonab-CD3e $(0.025 \mu \mathrm{g} / \mathrm{ml})$ for 3 days in the presence of mitomycin $\mathrm{C}$ (BioLegend)-treated antigen-presenting cells (APCs; 1: 1), and proliferation levels were detected with FACS. The GMSC proliferation abilities were tested with CCK-8 kit (Dojindo) according to the manufacturer's instructions. The survival and apoptosis rate of before and after GMSC injection (day 4) was detected by FACS. The osteogenic and adipogenic differentiation capabilities of sorted GMSCs were also evaluated as follows: cells were plated at $5 \times 10^{4}$ cells/well in 24-well plates overnight and replaced with osteogenic induction medium supplemented with dexamethasone (Sellec), L-glutamine (Gibco), ascorbic acid (Sigma), and $\beta$-glycerophosphate (Sigma). For adipogenic differentiation, adipogenic medium containing $10 \mu \mathrm{M}$ human insulin (Sigma), $1 \mu \mathrm{M}$ dexamethasone, $200 \mu \mathrm{M}$ indomethacin (Sigma), and $0.5 \mathrm{mM}$ 3-isobutyl-1-methylxanthine (Sigma) was used. After $4-5$ weeks, bone mineralization was assayed by Alizarin Red S (Sigma) staining to detect osteogenic differentiation capabilities of GMSCs, and adipogenic differentiation of GMSCs was assayed by staining with Oil Red O (Sigma) to detect intracellular lipid vacuole characteristic of adipocytes at 2 weeks [18].

Short-term and long-term toxicity test in rhesus monkeys In short-term toxicity tests, $5.0 \times 10^{7} / \mathrm{kg}$ of GMSCs was transplanted i.v. into monkeys, and $0.9 \% \mathrm{NaCl}$ solution was injected as a negative control. Weight, blood, and biochemical tests were conducted at the time of pre-treatment and at 2,7 , and 15 days following administration. In long-term toxicity tests, $0.3 \times 10^{7}, 0.6 \times 10^{7}$, and $1.2 \times 10^{7} / \mathrm{kg}$ of GMSCs, respectively, were transferred into monkeys every 10 days over a 30 -day period. Biochemical indices, electrocardiography, ophthalmic testing, and urinalysis were conducted at the first-dose period (FP, 10 days after first dosing), at the withdrawal period (WP, 10 days after the third dosing) and at the recovery period (RP, 6 weeks after withdrawal).

\section{Statistical analysis}

All results were expressed as the mean \pm standard deviation. The available data were analyzed using SPSS statistical software version 22.0. Comparisons between groups were performed by analysis of variance (ANOVA) followed by LSD test and Games-Howell test when results from ANOVA were significant. $P<0.05$ was considered to be statistically significant.

\section{Results}

GMSCs did not induce inflammatory response in vessel or muscle of rabbit, nor did they give rise to hemolysis in vitro

The results of the vascular stimulation test showed that there was neither evidence of vascular congestion nor 
swelling of the surrounding tissues in the GMSCs group, mirroring findings similar to those seen in the control group receiving $0.9 \% \mathrm{NaCl}$ solution (Fig. 1a). H\&E staining showed no lymphocytic infiltration in the GMSCs treated group (Fig. 1b). Thus, GMSCs did not cause vascular stimulation.

Local muscular tolerance study was another important toxicity parameter to evaluate the irritation potential of the GMSCs. The results of muscular irritation test are presented as follows: at 24 and 48 $\mathrm{h}$ after injection, macroscopic observation, and histopathological examination revealed the horizontal stripes of the muscle fiber to be clear, with no intercellular congestion between muscles nor muscle pathological changes or differences between the GMSCs group and the $0.9 \% \mathrm{NaCl}$ solution group (Fig. 1c). These results indicate that GMSCs do not cause muscle irritation.

In the hemolysis test, results showed no evidence of hemolysis in either the GMSC group or the negative control group after $3 \mathrm{~h}$ of incubation. The positive control group resulted in a uniformly red and transparent color due to the lysed erythrocytes. No erythrocyte sedimentation was observed. This test indicates that the GMSCs had no effect on hemolysis (Fig. 1d).
GMSCs have no effect on systemic anaphylaxis in beagles and passive anaphylaxis in rats

We next evaluated whether GMSCs could cause a systemic allergic response in a dog model. Our data have demonstrated that beagles exhibited no behavioral changes (including expansion of superficial vessels, such as the mouth, ear, nose, and skin flushing, uneasiness, head hitting against the wall, unsteady standing, falling repeatedly, vomiting repeatedly, salivation, incontinent urination, and defecation) in both low- and high-dose groups that was similar to the $0.9 \% \mathrm{NaCl}$ solution group (Table 1). Next, we checked the serum levels of histamine and these result indicated that both of low and high dose of GMSCs did not cause increased level of histamine in post-stimulation by contrast to pre-sensitization and pre-stimulation (Additional file 1: Figure S1).

Passive anaphylaxis-skin Arthus reaction is a sort of local type III hypersensitivity reaction that are involved in the deposition of antigen (Ag) and antibody (Ab) complexes which mediated acute inflammatory tissue injury [40]. Our data are presented as follows: after $48 \mathrm{~h}$, Evans blue solution was injected intravenously and the amount of dye leakage was measured after $30 \mathrm{~min}$. Although no blue spots in the skin developed in high and low doses of GMSCs (Fig. 2) $(p<0.05)$, cutaneous blue spots were prominently observed in animals in the

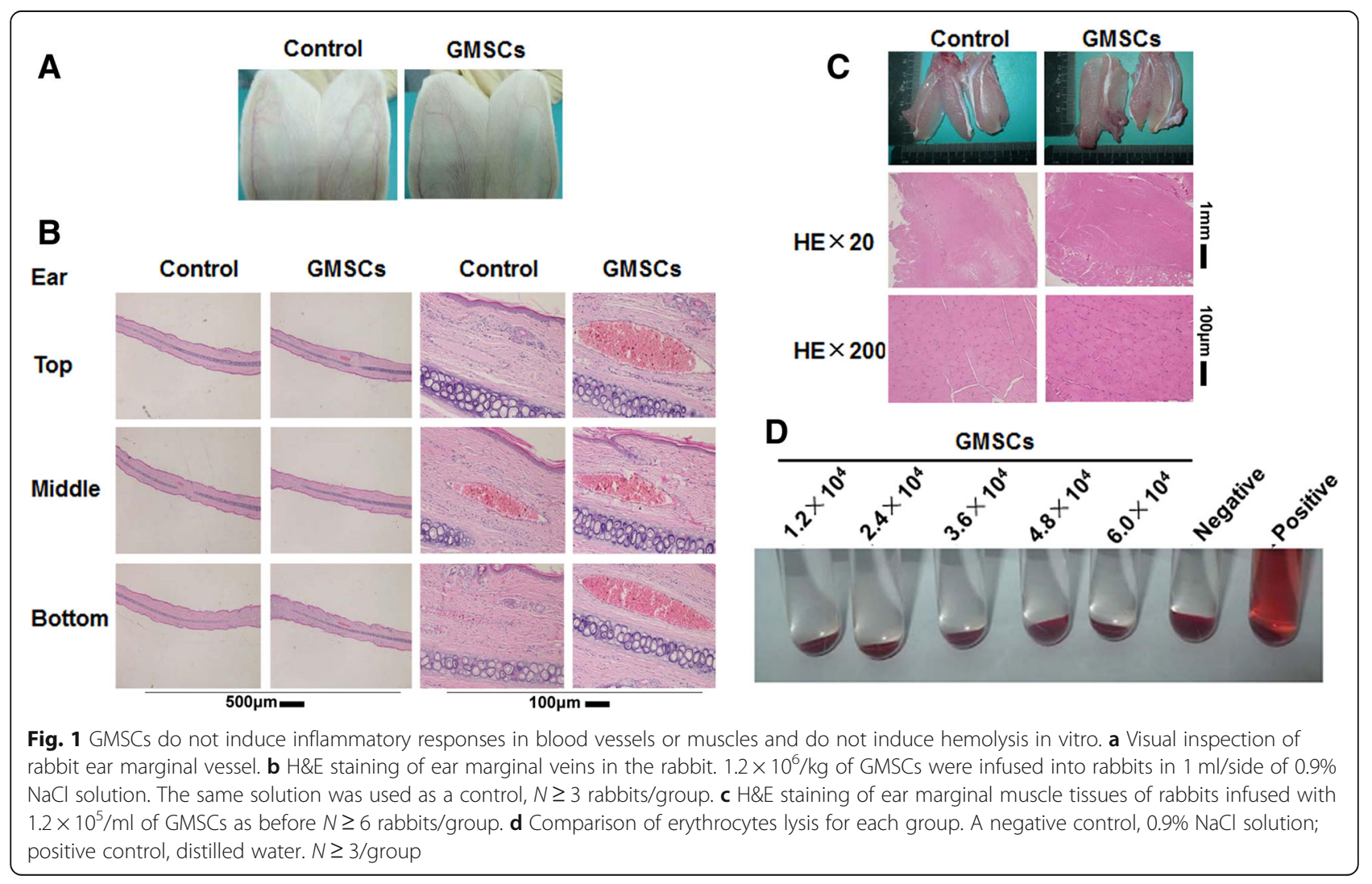


Table 1 Judgment of the typical behavior on beagles

\begin{tabular}{llllllll}
\hline Group & Gender & \multicolumn{1}{l}{ Time course } & & & \\
\cline { 3 - 7 } & & Pre-sensitization & Day 0 & Day 2 & Day 4 & Day 18 & Day 19 \\
\hline NC & F & - & - & - & - & - & - \\
& M & - & - & - & - & - & - \\
LD & F & - & - & - & - & - & - \\
& M & - & - & - & - & - & - \\
HD & F & - & - & - & - & - & - \\
& M & - & - & - & - & - & - \\
\hline
\end{tabular}

"-" represents no symptoms. $N C$ negative control, $L D$ low dosage group, $H D$ high dosage group, $F$ female, $M$ male. Three times of sensitization was individually conducted in day 0 , day 2 , and day 4 . Stimulation was performed after 14 days (day 18 )

BSA-treated positive control group. This result demonstrates that GMSCs did not result in the deposition of antigen-antibody complexes to ignite the anaphylaxisskin Arthus reaction that is a type of local type III hypersensitivity reaction.

\section{GMSCs have no adverse effects in short- and long-term toxicity test in rats}

In order to evaluate the potential toxicity of GMSC administration and to establish an initial dose of usage and the safety spectrum of repeated usage in clinical trials, we next examined the short- and long-term toxicity of GMSCs. Aliquots of $6.0 \times 10^{7} / \mathrm{kg}$ of GMSCs were injected intravenously into rats (a 60-fold dose relative to patients) who merely appeared with transient decreased light activity and tachypnea at $2 \mathrm{~min}$. In contrast to rats receiving the $1.2 \times 10^{8} / \mathrm{kg}$ of GMSCs (a dose equivalent with 120 -fold of a patient dose), developed decreased activity and shortness of breath over 3 to $5 \mathrm{~min}$. Although 95\% rats died, there were no abnormal hematologic or pathologic changes in the important organs and tissues examined in either of the two dosage groups. It is probable that the high dose of GMSCs may have caused an accumulation of GMSCs in the lung resulting in physical death. Importantly, the result of short-term toxicity indicates that $1.2 \times 10^{8} / \mathrm{kg}$ is the maximum dosage of GMSCs that were used for clinical therapy.

We next observed the long-term toxicity of GMSC infusion in rats. The weight of rats in the GMSC-treated group was slightly lower, while food consumption, ophthalmic tests, and urinalyses were similar to the control group (data not shown). The results of hematologic analyses are shown in (Fig. 3a, b and Additional file 1: Figure S2A). When infusion of $1.5 \times 10^{7}$ and $3.0 \times 10^{7} / \mathrm{kg}$ (a dose equivalent to a 15- and 30-fold dose in patients) of GMSCs, mean platelet volume (MPV) and activated partial thrombin time (APTT) in withdrawal period and MPV in recovery period was significantly lower than the control group $(p \leq 0.01)$. Additionally, in the group receiving $3.0 \times 10^{7} / \mathrm{kg}$ of GMSCs, MPV was also reduced during the first phase of dosing. Moreover, thrombin time (TT) in the 1.5 and $3.0 \times 10^{7} / \mathrm{kg}$ of GMSC group in WP, and $7.5 \times 10^{6} / \mathrm{kg}$ (7.5-fold of patient dose) of GMSC

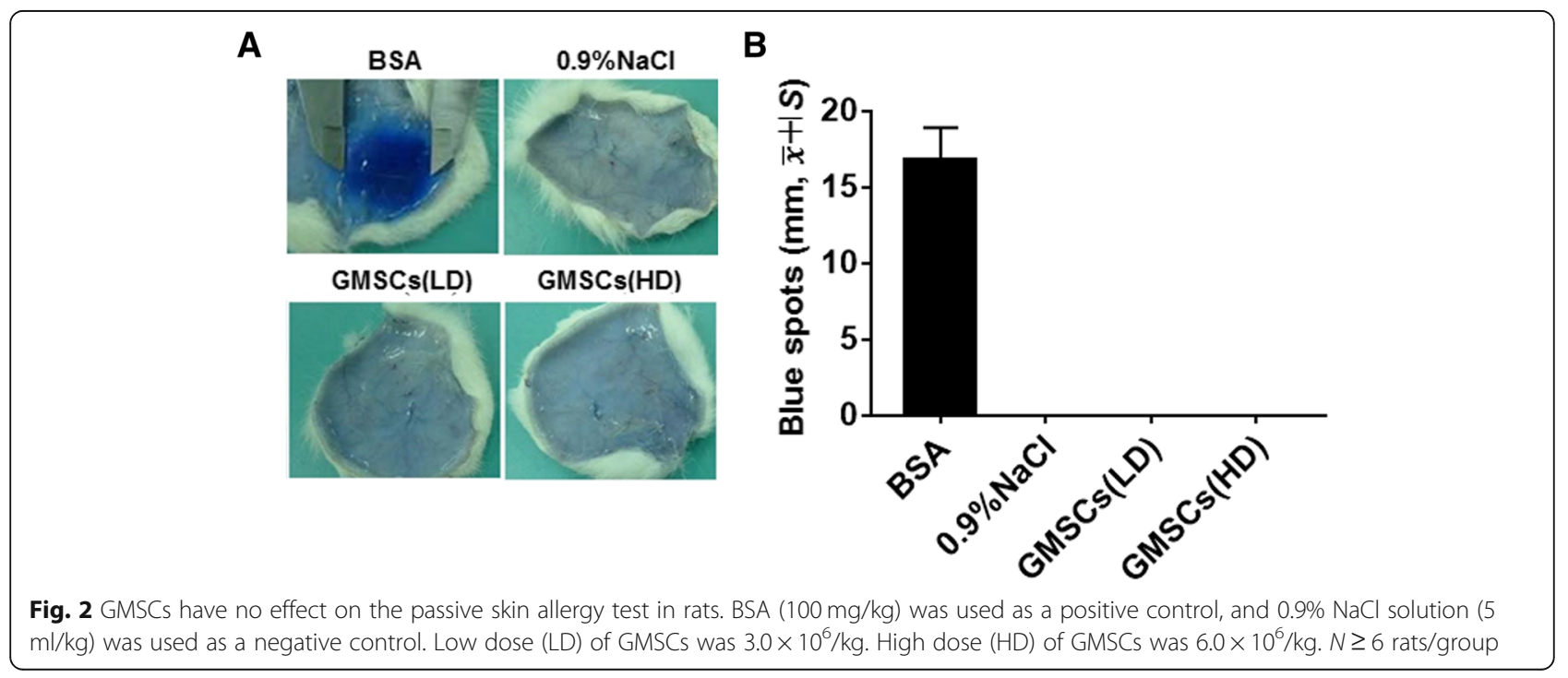


A

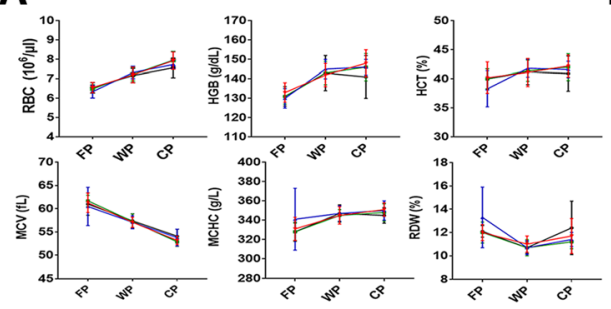

B

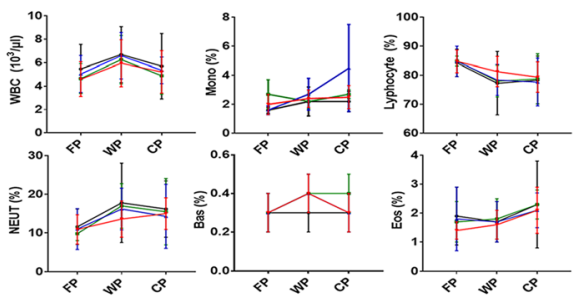

C
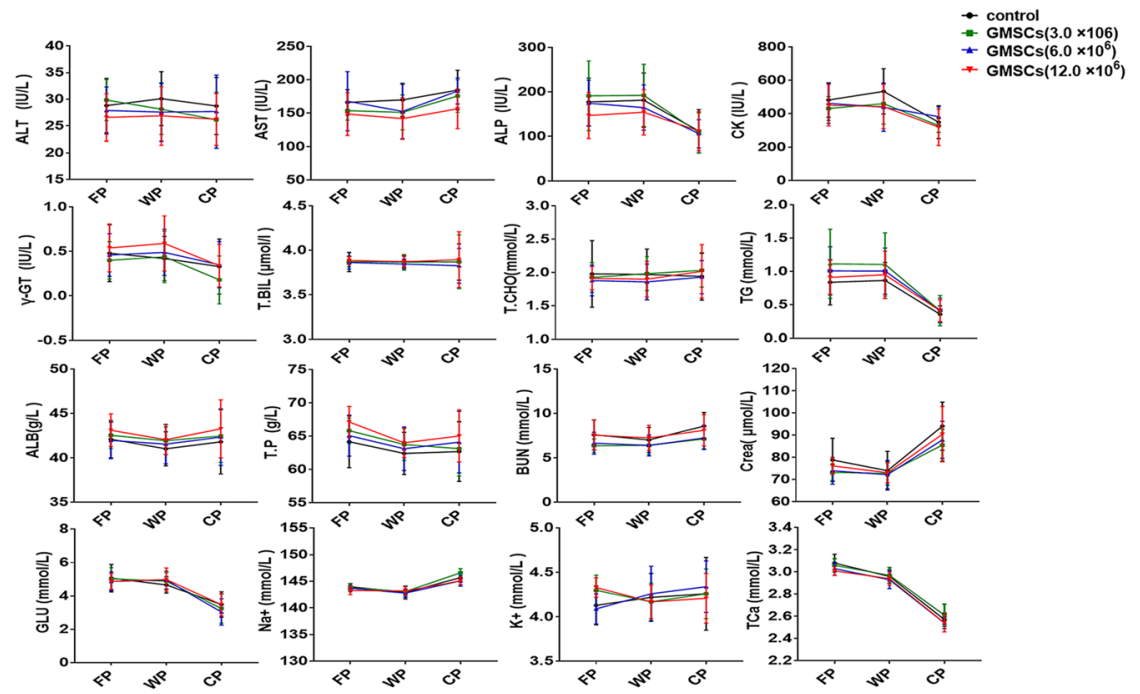

D
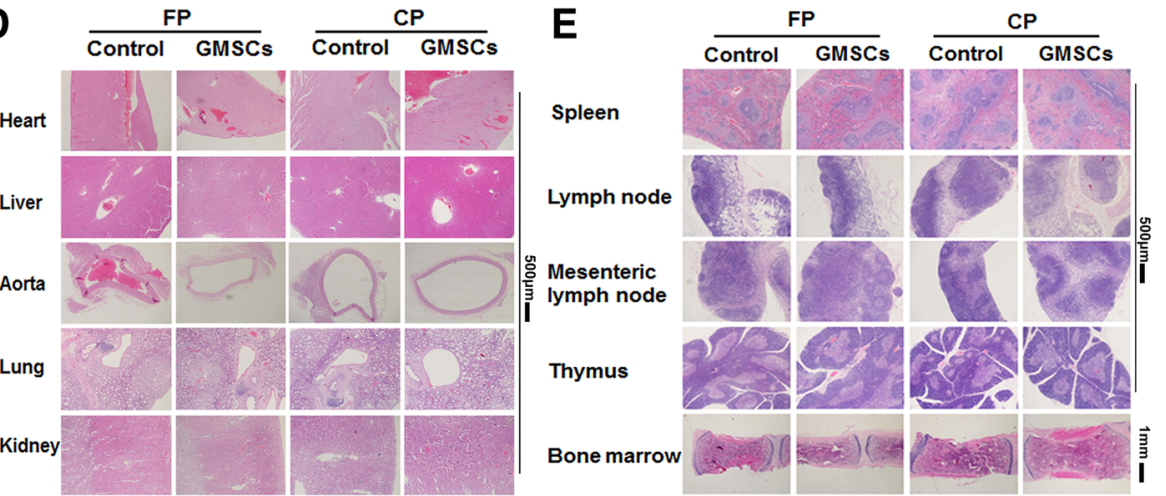

Fig. 3 GMSCs have no side effects in long-term toxicity test in rats. a GSMC influence on RBC related indexes, including hemoglobin concentration $(\mathrm{HGB})$, hematocrit $(\mathrm{HCT})$, erythrocyte mean corpuscular volume (MCV), mean corpuscular-hemoglobin concentration (MCHC), red blood cell distribution width (RDW), and (b) the percentage (\%) of immune cells, including white blood cells (WBC), lymphocyte, monocytes (MONO), neutrophilic granulocyte (NEUT), basophilic granulocyte (BASO), eosinophilic granulocyte (EOS) by infusing GMSCs into rats in the first dose period (FP), withdrawal period (WP), and convalescence period (CP) respectively. GMSC effect on biochemical indexes (c) and H\&E staining $(\mathbf{d}-\mathbf{e})$ of parts of important organ of rats. The data indicate the mean \pm SD of three separated experiments. ${ }^{*} p<0.05,{ }^{* *} p \leq 0.01$. $N \geq 6$ rats/group

group, the percentages of monocytes (MONO) in FP, and basophiles (BASO) in RP were slightly increased in contrast to the control group $(p \leq 0.01)$. A dose-response relationship is observed in all these measurements which conformed to hematologic references. Beyond that, indices of long-term toxicity tests were not different from $0.9 \% \mathrm{NaCl}$ solution group.

Some biochemical indexes are shown in (Fig. 3c). Both in $0.75 \times 10^{7} / \mathrm{kg}(p<0.05)$ and $3.0 \times 10^{7} / \mathrm{kg}(p \leq 0.01)$ of
GMSCs, aspartic transaminase (AST) was also decreased in $3.0 \times 10^{7} / \mathrm{kg}$ GMSC group in withdrawal period. In contrast, concentrations of $\mathrm{K}^{+}$of 0.75 and $3.0 \times 10^{7} / \mathrm{kg}$ GMSCs and $\mathrm{Na}^{+}$of $0.75 \times 10^{7} / \mathrm{kg}$ were incremental during the recovery phase in contrast to control group $(p<0.05)$. A dose-response relationship was observed in all these measurements which conformed to biochemical references.

$H \& E$ staining (Fig. 3d, e and Additional file 1: Figure S2B) indicated that GMSCs do not have adverse effects 
on infiltration of inflammatory cells into some important tissue and organs, e.g., heart, liver, spleen, kidney, and thymus. Visceral weights are provided (Additional file 1: Figure S2C). When GMSCs are infused into rats, both the 1.5 and $3.0 \times 10^{7} / \mathrm{kg}$ dose caused an increase of spleen weight in FP $(p \leq 0.01)$. An increase of heart weight during the first dosing phase was observed in $3.0 \times 10^{7} / \mathrm{kg}$ group $(p \leq 0.01)$. The $0.75 \times 10^{7} / \mathrm{kg}$ dose did not result in any organ size abnormalities nor did they produce any side effects. They also demonstrated an excellent long-term (repeated dosing) safety profile.

We also evaluated the safety of GMSC infusion in two autoimmune disease models: autoimmune arthritis and lupus. Our results showed that despite a 10-fold increase in dosage relative to those used in clinics, side effects did not emerge in GMSCs infused models until 20 days after cell injection. Moreover, there were no notable differences in weight, hematological, and biochemical data between the $0.9 \% \mathrm{NaCl}$ solution group and GMSC group in either autoimmune disease model (Additional file 1: Figure S3). Thus, GMSCs appear to be safe either in health or the disease state.

\section{GMSCs do not induce reverse mutation of S. typhimurium and chromosomal aberration in the $\mathrm{CHL}$ line}

An Ames test was used in order to determine whether GMSCs resulted in genotoxicity. Figure $4 \mathrm{a}$ and $\mathrm{b}$ present the results of metabolic activity as a marker of mutagenesis which requires catalysis by the $S 9$ mix. The results of non-metabolic activity (without $\mathrm{S} 9 \mathrm{mix}$ ) are also presented (Fig. 4c, d). These results detect mutagenesis events that can directly induce mutations in S. typhimurium. The results were identical between the GMSC group and the negative group and demonstrate that there was no diversification of reverse mutation of colony-forming units detected $(p \geq 0.05)$. The positive control also clearly demonstrates that reverse mutations in colony-forming units were clearly increased $(p \leq 0.01)$ both under conditions of non-metabolic activity and metabolic activity. These data suggest that GMSCs most likely play no role in causing reverse mutation and genotoxicity of S. typhimurium.

To evaluate whether GMSCs induce chromosomal aberration in the CHL, various doses of GMSCs were pre-incubated with $\mathrm{CHL}$ for $48 \mathrm{~h}$. Under conditions of either metabolic activity or non-metabolic activity conditions, none of the doses of GMSCs had a striking impact on CHL aberration rates $(<5 \%)$ relative to the negative group (aberration rates $<5 \%$ ) over an incubation period of $6 \mathrm{~h}(p \geq 0.005)$. Meanwhile, $40 \mu \mathrm{g} / \mathrm{ml}$ of $\mathrm{CP}$ and $0.1 \mu \mathrm{g} / \mathrm{ml}$ of mitomycin C (used as a positive control for non-metabolic and metabolic conditions respectively) in this system, aberration rates of $\mathrm{CHL}$ were near $10 \%$ that was notably higher than negative group $(p \leq 0.01)$ (Fig. 4e, f).

\section{The distribution and time course of GMSCs in organs of rats}

In order to determine the GMSCs homing and half-life period in vivo, we transplanted CM-DI pre-treated GMSCs into rats and observed chemotactic effects and distribution of GMSCs. GMSCs were detected only in the spleen (Fig. 5a), liver (Fig. 5b), and lung (Fig. 5c) on days 10 and 30 post-injection. However, it is significant that GMSCs persisted in the lung for 58 days. Nevertheless, fewer GMSCs persisted in other organs and tissues.

We next asked whether the biological characteristics of GMSCs changed following injection into mice. GMSC distribution was monitored on the lung, spleen, lymph nodes, and peripheral blood on days 1 to 4 after injection. As shown in Additional file 1: Figure S4A, GMSCs were primarily found in the lung early and then could be found distributed to the lymph nodes later, indicating that they may have immunoregulatory roles. GMSCs were sorted from the spleen, lymph node, lung, and peripheral blood after they had been transferred. We found that the phenotypes and suppressive activity were nearly identical to that observed prior to injection (Additional file 1: Figure S4B and C). Moreover, there was no change in proliferation abilities of these cells before and after injection (Additional file 1: Figure S4D). We also found that there were no differences in apoptosis rates between sorted GMSCs (4 days after injection) and GMSCs prior to injection, and both cell populations survived well (Additional file 1: Figure S4E). Furthermore, GMSCs that were sorted from mice 4 days after injection maintained osteogenic and adipogenic capacities (Additional file 1: Figure S4F). Thus, GMSCs maintain their phenotype and functional activity in vivo at least during the period of observation used in this study.

\section{Short-term and long-term toxicity of GMSC infusion in rhesus monkey}

Since the study of toxicology is of particular significance in the evaluation of safety of cell-based therapy, and its performance is required for the proposed final product [41], and short-term and long-term toxicity of GMSCs was further conducted in the monkey, a species closer to the human than other animal models. In short-term toxicity tests, $5.0 \times 10^{7} / \mathrm{kg}$ of GMSCs which is equivalent with 50 -fold of clinical dose in patients were transferred to monkeys, and results revealed that GMSCs did not significantly affect the weight of monkeys $(p \geq 0.05)$. Hematologic (Additional file 1: Figure S5A and S5B) and biochemical analyses (Additional file 1: Figure S5C) showed that white blood cells (WBC), neutrophilic granulocyte (NEUT, \%), alkaline phosphatase (ALP), and $\mathrm{Na}^{+}$ in GMSC-treated group were significantly lower than those in control group at the same points $(p<0.05)$ at the conclusion of the test. However, the $\gamma \mathrm{GT}$ and $\mathrm{Na}^{+}$in 


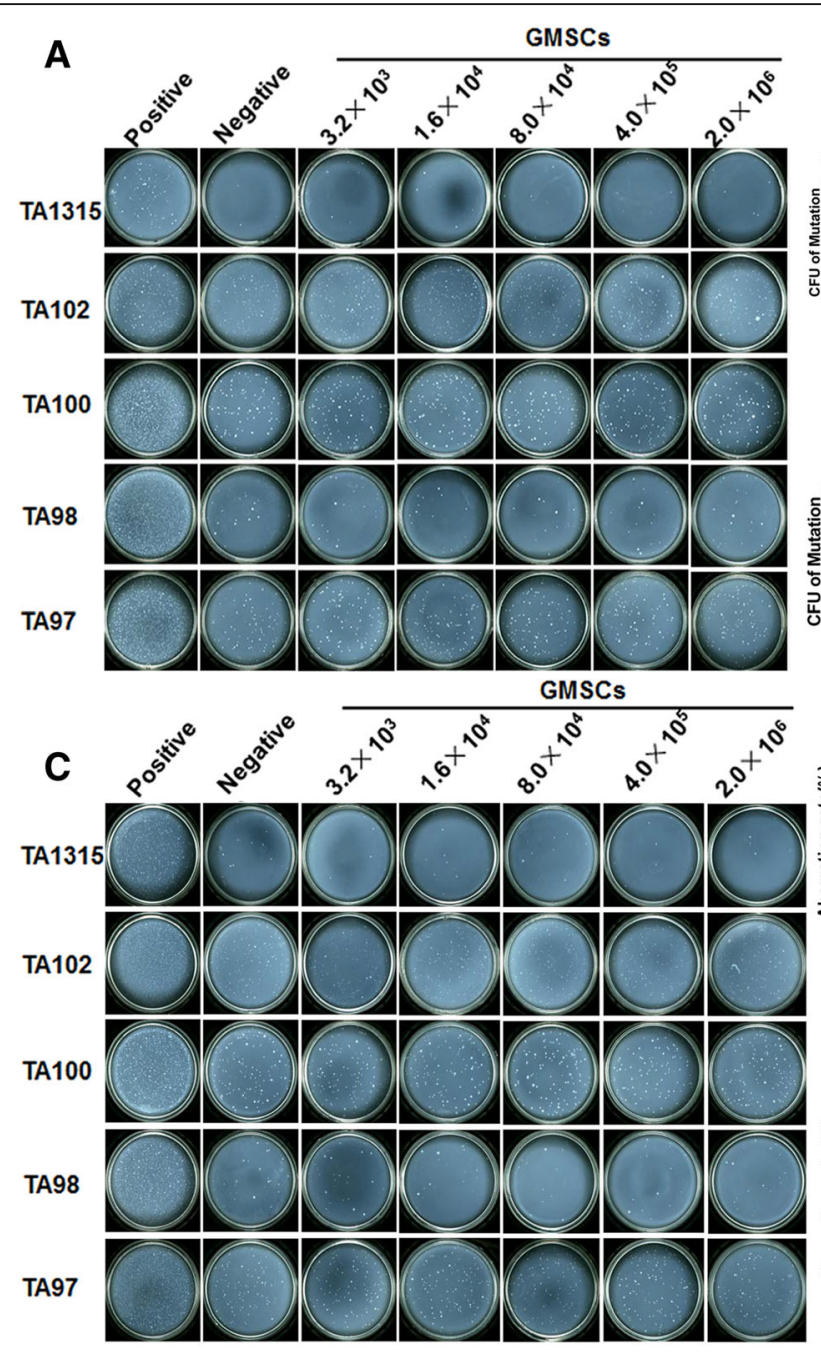

\section{B}
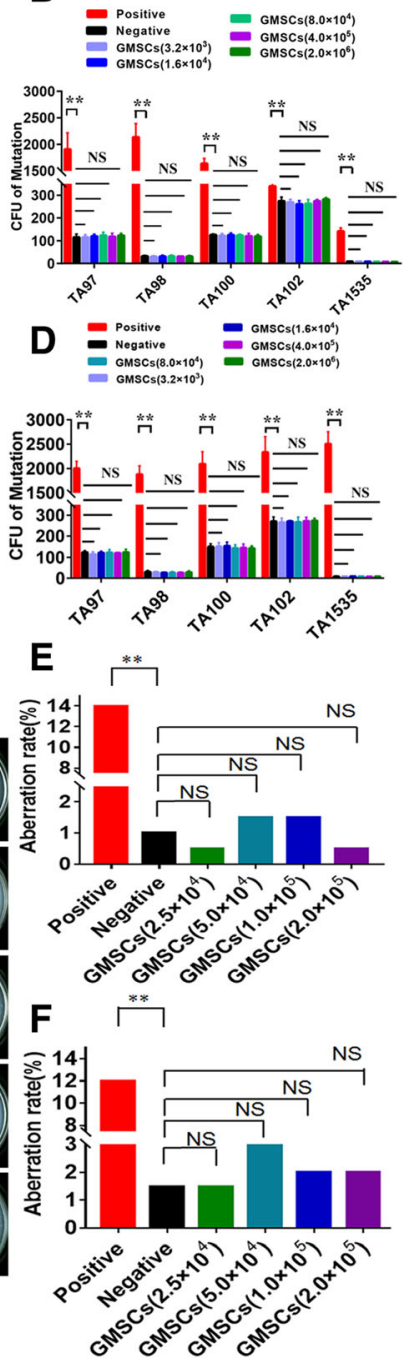

Fig. 4 GMSCs did not cause reverse mutation of S. typhimurium and chromosome aberration of CHL strain. a, b Under conditions of metabolic activation (presence of S9), positive control $\left(50 \mu \mathrm{g} /\right.$ dish Dexon was for TA97, TA98, and TA102 strains, $2.0 \mu \mathrm{g} /$ dish NaN $\mathrm{N}_{3}$ was for TA100 and TA1535 strains), c, d non-metabolic activation (absence of S9), positive control (50 $\mu \mathrm{g} / \mathrm{dish}$ Dexon was for TA97, TA98, and TA102 stains: $2.0 \mu \mathrm{g} / \mathrm{dish}$ NaN3 was for TA100 and TA1535 stains). Meanwhile, $0.1 \mathrm{ml} /$ dish $0.9 \% \mathrm{NaCl}$ was as negative control. e Chromosome aberration rates under metabolic activation (with $\mathbf{S 9} \mathrm{mix}$ ) and $\mathbf{f}$ non-metabolic activation (without $\mathrm{S9}$ mix) with 6-h GMSC treatment. CP and mitomycin C served as a positive control with and without $\mathrm{S} 9 \mathrm{mix}$, and $0.9 \% \mathrm{NaCl}$ solution was used as a negative control. The data represent the mean \pm SD of three separated experiments. NS means no significance; ${ }^{*} p<0.05,{ }^{* *} p \leq 0.01$ ). $N \geq 3$ /group

pre-treated GMSCs $(p<0.05)$ and in the second day of administration $(p \leq 0.01)$ is only slightly higher than the control group. Interestingly, there was no obvious clinical presentation in these monkeys and other indexes were similar to control $(p \geq 0.05)$. Electrocardiogram analysis demonstrated that the heart rate was slightly slower $(p<0.05)$, and S-T segment $(p \leq 0.01)$ and Q-T interval $(p \leq 0.01)$ were more prolonged than the control group when the high dose of GMSCs was infused into monkeys, but still within normal limits and range (Additional file 3: Table S2). Although the Q-T interval delay $(p \leq 0.01)$ contributed to the heart rate, there were no abnormal presentations or death in contrast to the control group.

In long-term toxicity tests, the weight $(p \geq 0.05)$, food consumption $(p \geq 0.05)$, bone marrow count $(p \geq 0.05)$, ophthalmic test, and urinalysis of monkeys with the different doses of GMSCs was more aligned with a normal range than that observed for the control group (data not shown). Blood (Fig. 6a, b and Additional file 1: Figure S6A) and biochemical indexes (Fig. 6c) showed that middle and high doses of GMSCs could induce WBC, glutamic-pyruvic transaminase (ALT), $\mathrm{Na}+$, and TCa to increase following the first dose and during the withdrawal 


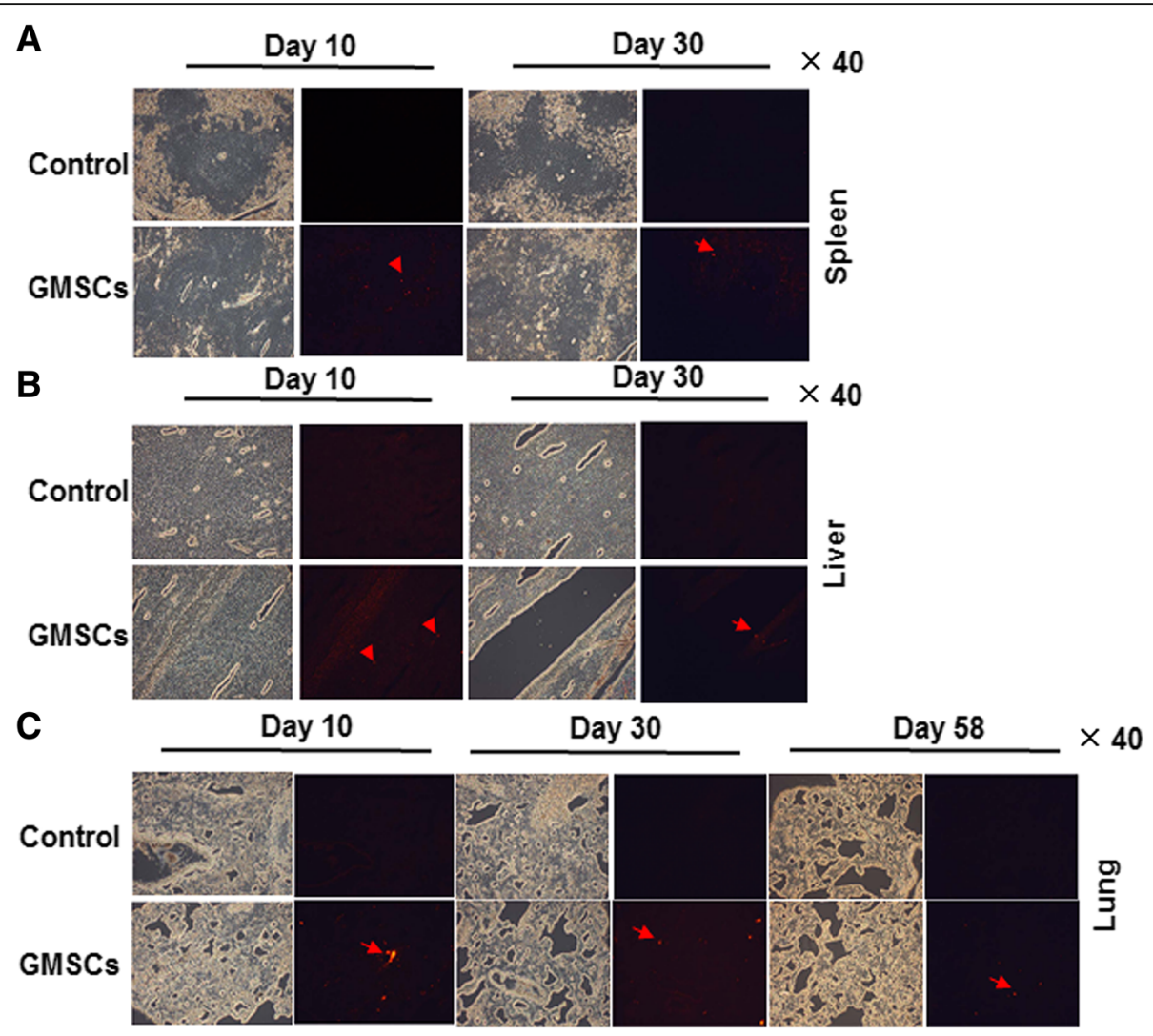

Fig. 5 The distribution and time course of GMSCs in organs of rats. a The distribution and duration in the spleen, $\mathbf{b}$ liver, and $\mathbf{c}$ lung of rats at 10, 30-, and 58-day time points. Red fluorescence represents CM-DI pre-treated GMSCs (arrowhead). $0.9 \% \mathrm{NaCl}$ solution-treated rats served as control. $N \geq 6$ rats/group

period. The BASO (\%) during the withdrawal period and the PT in the first-dose period also increased. We also found that MONO (\%) decreased during the withdrawal period. We observed that when injected with the middle dose of GMSCs, the following parameters were also influenced: ALT, WBC, BASO (\%), lymphocytes (LYMPH, \%), MONO (\%), and TCa. However, the only changes in blood parameters observed for the low dose of GMSCs were decreased platelet (PLT) and BASO\% compared to control. It should be noted that the changes in these indexes were reversible and within normal limits. Despite these observations, H\&E staining revealed no differences in important viscera between monkeys pre-treated with GMSCs and those in the control group (Fig. 6d, e and Additional file 1: Figure S6B). While infusion of GMSCs appears to increase spleen weight, it only does so transiently (Additional file 1 : Figure S6C). Although the electrocardiographic abnormalities manifested in GMSC treated monkeys resulted in a more prolonged QRS than control animals' recovery periods $(p \leq 0.01)$ (Additional file 4: Table S3), they were still within the normal range. Other indexes, e.g., morphologic analysis of bone marrow cells (Additional file 5: Table S4) were similar to the control group $(p \geq 0.05)$.

\section{Discussion}

MSCs are immunosuppressive multipotent cells capable of differentiating into many different varieties of specialized cells [42]. Recently, a novel subset of MSCs that originated from human gingival tissue (GMSCs) was found to possess the homologous capacity as other MSCs that maintain immune homeostasis and prevent autoimmunity. GMSCs are particularly effective at suppressing human PBMC-initiated xenogenic responses in a humanized GVHD model [3, 18, 23]. Moreover, GMSCs exhibit a high proliferative rate relative to other adult dental tissues such as dental pulp stem cells (DPSCs), periodontal membrane stem cells PDLSCs, and even BMSCs. Additionally, GMSCs are isolated from human gingiva making them an easily accessible tissue to retrieve from the oral cavity or as a discarded tissue sample following certain dental procedures [18]. These characteristics suggest that GMSCs could represent a novel source of MSCs for the treatment of autoimmune and inflammatory diseases. Despite the advantages of GMSCs in cell therapy, there is an obvious lack of evidence detailing their safety in either animals or humans. Since safety of a cellular product remains the most important 
A

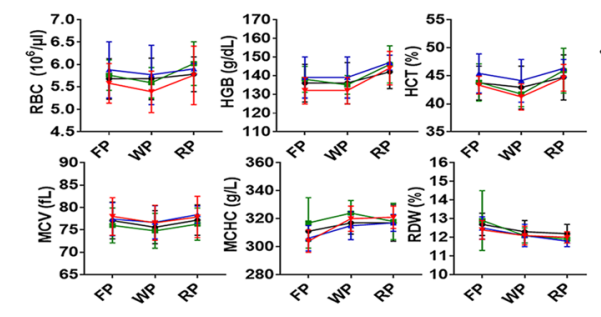

C

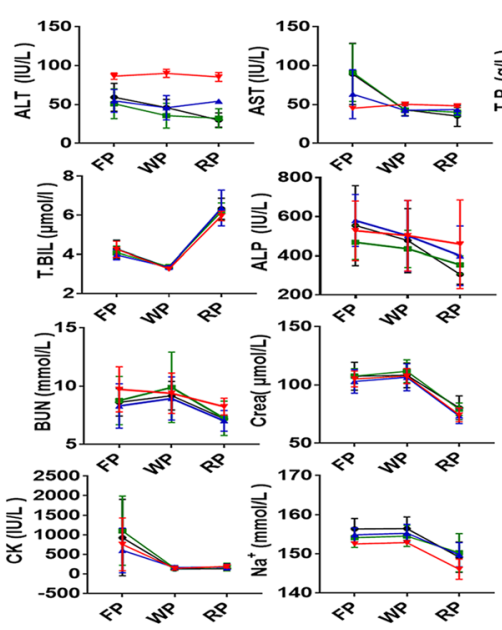

D

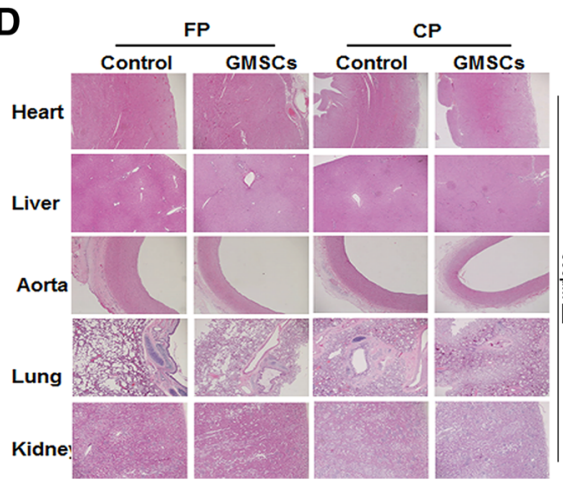

B
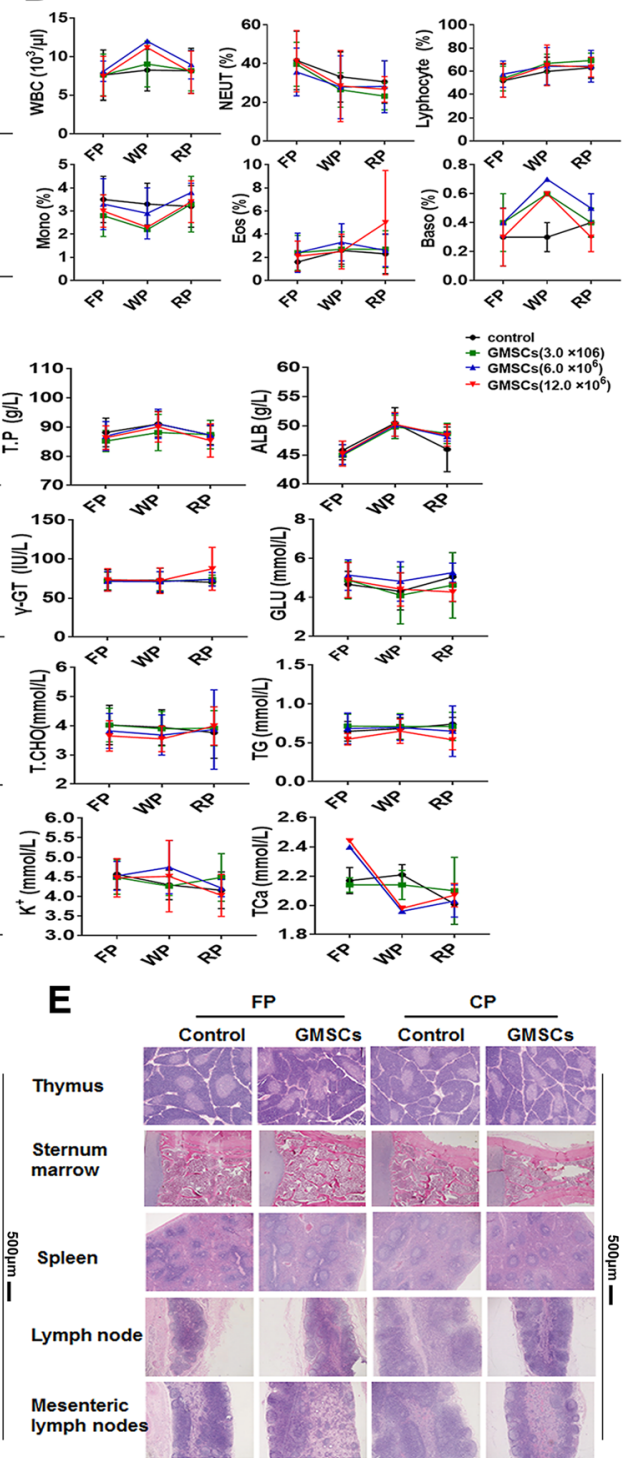

Fig. 6 GMSCs do not influence long-term toxicity in rhesus monkeys. a Variety of blood indexes including RBC, HGB, HCT, MCV, MCHC, and RDW, and $\mathbf{b}$ the percentage (\%) of immune cells, including WBC, MONO, NEUT, BASO, and EOS, in monkeys during the first-dose period (FP), withdrawal period (WP), and convalescence period (CP), respectively. c GMSCs effect on biochemical indexes and H\&E staining (d, e) in an important organ of rhesus monkeys. The data represent the mean \pm SD of three separated experiments. ${ }^{*} p<0.05,{ }^{* *} p \leq 0.01$.

$N \geq 10$ animals/group

criteria for human applications [43, 44], such studies must be evaluated in acute and chronic in vivo models and must encompass [14] the examination of major organs, neighboring tissues, blood chemistry, and blood cell counts after the transplantation into the in vivo models [45].

Quality control (QC) of GMSCs is necessary to be performed prior to their safety evaluation. QC includes cell purity, differentiation activity, and a pathogenic microorganism test in the suspension of GMSCs. Additionally, previous studies have demonstrated that GMSCs consistently express CD29, CD73, and CD90/Thy-1 from passages 2 to 6 and that they can be steadily expanded in vitro while still maintaining their early phenotypes until passage 6 [18]. With this in mind, we opted to use cells at the third passage. It will be interesting to determine whether different passages of GMSCs have different biological features, a notion that richly deserves an independent study in the future.

Previous studies have shown that intravascular infusion of adipose-derived MSCs may lead to occlusion in the distal microvasculature because of the large cell size [26]. In the present study, we firstly provided evidence, 
under appropriate dosing conditions that GMSC infusion did not result in vascular and muscular stimulation following intravenous and intramuscular administration. GMSCs did not clog in the lung but distributed to lymph nodes and other organs. We are still unclear whether the size difference between different MSC populations will affect their distribution. GMSCs did not induce inflammatory responses at injection sites. We next demonstrated that GMSCs did not destroy erythrocyte integrity by hemolytic testing in vitro. Since injection is the generally acceptable form of administration of GMSCs for cell-based therapy, it is necessary to ensure the safety of various routes of injection before clinical application. Our findings suggest that GMSCs can be applied to multiple diseases through vascular and muscular routes of administration.

Our results also addressed concerns of allergenicity of GMSCs by performance of passive anaphylaxis studies in the rat skin and systemic allergic symptoms in a dog model. We presented evidence that appropriate dose of GMSCs did not cause any passive allergic response, also known as a local type III hypersensitivity reaction. Furthermore, in our experiments conducted in beagles, there were no allergic reactions nor behavioral changes observed, even in high-dose groups. This suggests that GMSCs can safely be used, even in large doses. We will address these issues by the following strategies to avoid this problem: a single dose of GMSCs will be rigorously controlled and autologous GMSCs derived from the patient will be used to provide enhanced safety in therapeutic trials [46].

When GMSCs were administrated in two groups with high doses (mimicking a maximum clinical dose of 60 and 120-fold respectively) for assessment of acute toxicity, we found there were transient and abnormal light responses detected in rats, including decreased activity tachypnea, and weight loss and self-healing in several minutes at low doses. Moreover, 95\% death rates occurred in rats at these high doses. This results suggest, therefore, that the optimal maximum tolerated dose is $6.0 \times 10^{7} / \mathrm{kg}$ in single administration. The long-term view of GMSC administration, suggested that GMSCs had no significant side effects on important organs or tissues, e.g., heart, liver, spleen, lung, and renal function in rats. Other assays, such as ophthalmic test and urinalysis, hematologic, and biochemical indexes, also showed that animals tolerated GMSCs under various conditions. Our studies included both normal animals and those expressing autoimmune diseases. A significant aspect of the toxicology study was that it included non-human primates (NHPs), which are closer to human physiology than other animal models and therefore data generated from NHPs provides more relevant safety data during the preclinical phase. In the studies using NHPs, our data concerning short- and long-term toxicity showed that electrocardiographic, ophthalmic test and urinalysis, hematology, and biochemical indexes of NHPs were all normal when GMSCs were infused in vivo. Collectively, these results suggest that repeated infusion of GMSCs can safely be performed for further research towards in clinical trials.

Tumorigenicity is another important parameter that should be evaluated in the assessment of long-term use of GMSCs. Yamaoka et al. has reported that BMSCs have a tumorigenesis capability, resulting in a long-term risk following the use of BMSCs [19, 28, 47]. BMSCs increase the proliferation, migration, and efficiency of mammosphere formation of tumor cells in vitro and suggested that the promotion of tumor growth in vivo may be also attributable in part to enhanced angiogenesis [48-50]. However, in the present study, we demonstrated GMSCs did not lead to genotoxicity and oncogenesis under therapeutic usage. This result is consistent with the findings of Tomar et al. showing that infusion of GMSCs did not have the tumorigenic potential $[18,51]$.

Information concerning the kinetics of GMSCs is essential in preclinical studies since kinetics provides reliable evidence for GMSC security and effectiveness, information that is crucial prior to use in clinical research. A report by Li et al. [52] suggests that MSCs are quickly trapped lungs, without any detectable homing to the liver and other organs after inferior vena cava infusion. However, in the present study, preliminarily exploration of chemotaxis and half-life duration in rats demonstrated that GMSCs following intravenous injection mainly distribute to the liver, spleen, and particularly in the lung, with GMSCs persisting for about 2 months. It is not clear why the distribution of GMSCs should be different from other MSCs. These differences merit future study. These findings are consistent with results of other groups that demonstrated systemic delivery of BMSCs was limited by entrapment of cells mainly in the lungs as well as in the liver and spleen [53, 54]. Since infused GMSCs may be localized in the lung and liver in animal models, it is likely that GMSCs have a great potential in the treatment of pulmonary and hepatic diseases.

\section{Conclusion}

In summary, we have conducted a comprehensive evaluation of the safety of GMSCs in this preclinical study. Our evidence strongly suggests that GMSCs have no apparent adverse effects in various animal models including autoimmune arthritis and lupus, particularly in NHPs. Additionally, GMSCs maintain their phenotype, vitality, and function after they are injected into the body. Thus, GMSCs could be a promising therapeutic means for treating many diseases that currently are not curable. 


\section{Additional files}

Additional file 1: Supplementary figures and legends. Figure S1. The changes of histamine in both low and high dose of GMSC-treated beagle dog groups. Figure S2. GMSCs have no side effects in the coagulation system and organs of rats. Figure S3. GMSCs have no notable side effects and toxicity in autoimmune disease models. Figure S4. GMSCs were recovered from mice. Figure S5. GMSCs did not affect short-term toxicity in rhesus monkeys. Figure S6. GMSCs have no side effects in the coagulation system and organs of monkeys. (DOCX 3891 kb)

Additional file 2: Table S1. Rating criteria of abnormal behavior. (XLS $26 \mathrm{~kb}$ )

Additional file 3: Table S2. Electrocardiogram of rhesus by intravenous injection of GMSCs in short-term toxicity test $(n=4, \bar{x} \pm S)$. (XLS 29 kb)

Additional file 4: Table S3. Electrocardiogram of rhesus by intravenous injection of GMSCs in long-term toxicity test ( $n=4, \bar{x} \pm S$ ). (XLS 29 kb)

Additional file 5: Table S4. Bone marrow count of rhesus by intravenous injection of GMSCs in long-term toxicity test $(n=4, \bar{x} \pm S)$. (XLS $31 \mathrm{~kb})$

\section{Abbreviations}

2-AF: 2-Aminofluorene; ALP: Alkaline phosphatase; ALT: Glutamic-pyruvic transaminase; APCs: Antigen-presenting cells; APTT: Activated partial thrombin time; AST: Aspartic transaminase; BASO: Basophils; BMSCs: Bone marrow mesenchymal stem cells; CFSE: Carboxyfluorescein succinimidyl ester; CHL: Chinese hamster lung fibroblast cell line; CP: Cyclophosphamide; FP: First-dose period; GLP: Good laboratory practice; GMSCs: Gingival mesenchymal stem cells; H\&E: Hematoxylin and eosin; HCT: Hematocrit; HGB: Hemoglobin concentration; LYMPH: Lymphocytes; MCHC: Mean corpuscular-hemoglobin concentration; MCV: Erythrocyte mean corpuscular volume; MONO: Monocytes; MPV: Mean platelet volume; MSCs: Mesenchymal stem cells; NEUT: Neutrophilic granulocyte; NHP: Non-human primate; PLT: Platelet; RDW: Red blood cell distribution width; RP: Recovery period; SIS-ECM: Small intestinal submucosa extracellular matrix; $\Pi$ : Thrombin time; WP: Withdrawal period; $\gamma \mathrm{GT}$ : $\gamma$-Glutamyl transpeptidase

\section{Acknowledgements}

We thank the Center of Immunology, Zhoushan City Hospital at Wenzhou Medical University, and the Department of Allergy and Clinical Immunology, First Affiliated Hospital of Guangzhou Medical University. We are also grateful to Dr. David Brand from the VA medical center Memphis.

\section{Funding}

This work was supported by the National Key R\&D Program of China (No. 2017YFA0105801), the National Natural Science Foundation of China (No. 81671611), the Natural Science Foundation of Guangdong Province of China (No. 2014A030308005), the Science and Technology Program of Guangzhou of China (Special Project on the Integration of Industry, Education and Research) (No. 201508020060), Program from Guangdong Introducing Innovative and Entrepreneurial Teams (2016ZT06S252), and NIH R61/33 AR073409 (to S.G.Z)

\section{Availability of data and materials}

All data and materials are available in the manuscript.

\section{Authors' contributions}

SGZ contributed to the conception and design, data analysis and interpretation, manuscript writing, and final approval of the manuscript. JZ, $J D$, and $X Z$ contributed to the collection and/or assembly of the data, data analysis and interpretation, manuscript writing, and final approval of the manuscript. JW, WZ, YC, BH, and JX contributed to the collection and/or assembly of data and final approval of the manuscript. FH and BS contributed to the collection and/or assembly of data, data analysis and interpretation, and final approval of the manuscript. JB contributed to the manuscript writing and final approval of the manuscript.

\section{Ethics approval}

All animal procedures were performed in accordance with Good Laboratory Practice (GLP), Technical Guidelines for Research on Allergic and Hemolytic Drug Stimulants, and Technical Guidelines for Toxicity Study of Single Drug Delivery. Rats, rabbits, and non-human primates were performed in accordance with the Institutional Ethical Guidelines for Animal Experiments developed by Zhejiang Academy of Medical Sciences (Y-AP-14012). Experiments in mice and beagles were conducted in accordance with the Institutional Ethical Guidelines for Animal Experiments developed by the Sun Yat-sen University (180106). Gingival tissues were obtained from patients who underwent tooth extraction procedures, and clinical aspects of this study were approved by the ethics committee of the Third Hospital at the Sun Yat-sen University (2018-02-195-01) and consent forms were signed by donors.

\section{Consent for publication}

Not applicable.

Competing interests

The authors declare that they have no competing interests.

\section{Publisher's Note}

Springer Nature remains neutral with regard to jurisdictional claims in published maps and institutional affiliations.

\section{Author details}

${ }^{1}$ Department of Clinical Immunology, Third Affiliated Hospital at the Sun Yat-sen University, Guangzhou, China. ${ }^{2}$ Division of Immunology and Rheumatology, Department of Internal Medicine, The Ohio State University College of Medicine, Columbus, USA. ${ }^{3}$ Division of Rheumatology, Department of Medicine, Milton S. Hershey Medical Center, Hershey, USA. ${ }^{4}$ Center of Immunology, Zhoushan City Hospital at Wenzhou Medical University, Wenzhou, China. ${ }^{5}$ Department of Laboratory Medicine, Third Affiliated Hospital at the Sun Yat-sen University, Guangzhou, China. ${ }^{6}$ Huize Biotech, LLC and Huifu Biotech, LLC, Zhoushan, China. ${ }^{7}$ Department of Allergy and Clinical Immunology, State Key Laboratory of Respiratory Disease, National Clinical Research Center of Respiratory Disease, First Affiliated Hospital of Guangzhou Medical University, Guangzhou, China. ${ }^{8}$ Department of Pediatrics and Microbiology-Immunology, Georgetown University Medical Center, Washington DC, USA.

Received: 12 February 2019 Revised: 8 May 2019

Accepted: 10 May 2019 Published online: 13 June 2019

\section{References}

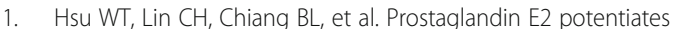
mesenchymal stem cell-induced IL-10+IFN-gamma+CD4+ regulatory T cells to control transplant arteriosclerosis. J Immunol. 2013;190:2372-80.

2. Ben-Ami E, Berrih-Aknin S, Miller A. Mesenchymal stem cells as an immunomodulatory therapeutic strategy for autoimmune diseases. Autoimmun Rev. 2011;10:410-5.

3. Chen M, Su W, Lin X, et al. Adoptive transfer of human gingiva-derived mesenchymal stem cells ameliorates collagen-induced arthritis via suppression of Th1 and Th17 cells and enhancement of regulatory T cell differentiation. Arthritis Rheum. 2013:65:1181-93.

4. Su W, Wan Q, Huang J, et al. Culture medium from TNF-a-stimulated mesenchymal stem cells attenuates allergic conjunctivitis through multiple antiallergic mechanisms. J Allergy Clin Immunol. 2015;136:423-32 e428.

5. Zhang $W$, Zhou $L$, Dang J, et al. Human gingiva-derived mesenchymal stem cells ameliorate streptozoticin-induced T1DM in mice via suppression of T effector cells and up-regulating Treg subsets. Sci Rep. 2017;7:15249.

6. Zhang $X$, Huang F, Chen $Y$, et al. Progress and prospect of mesenchymal stem cell-based therapy in atherosclerosis. Am J Transl Res. 2016;8:4017-24.

7. Friedenstein AJ, Chailakhjan RK, Lalykina KS. The development of fibroblast colonies in monolayer cultures of Guinea-pig bone marrow and spleen cells. Cell Tissue Kinetics. 1970;3:393-403.

8. Lee M, Jeong SY, Ha J, et al. Low immunogenicity of allogeneic human umbilical cord blood-derived mesenchymal stem cells in vitro and in vivo. Biochem Biophys Res Commun. 2014;446:983-9.

9. Oh W, Kim DS, Yang YS, et al. Immunological properties of umbilical cord blood-derived mesenchymal stromal cells. Cell Immunol. 2008;251:116-23. 
10. Kim JM, Lee ST, Chu K, et al. Systemic transplantation of human adipose stem cells attenuated cerebral inflammation and degeneration in a hemorrhagic stroke model. Brain Res. 2007;1183:43-50.

11. In 't Anker PS, Scherjon SA, Kleijburg-van der Keur C, et al. Amniotic fluid as a novel source of mesenchymal stem cells for therapeutic transplantation. Blood. 2003;102:1548-9.

12. Chang CJ, Yen ML, Chen YC, et al. Placenta-derived multipotent cells exhibit immunosuppressive properties that are enhanced in the presence of interferon-gamma. Stem Cells. 2006;24:2466-77.

13. Park $S$, Choi $Y$, Jung $N$, et al. Myogenic differentiation potential of human tonsil-derived mesenchymal stem cells and their potential for use to promote skeletal muscle regeneration. Int J Mol Med. 2016;37:1209-20.

14. Lei M, Li K, Li B, et al. Mesenchymal stem cell characteristics of dental pulp and periodontal ligament stem cells after in vivo transplantation. Biomaterials. 2014;35:6332-43.

15. Fernandes KJ, McKenzie IA, Mill P, et al. A dermal niche for multipotent adult skin-derived precursor cells. Nat Cell Biol. 2004;6:1082-93.

16. Zong Z, Li N, Ran X, et al. Isolation and characterization of two kinds of stem cells from the same human skin back sample with therapeutic potential in spinal cord injury. PLoS One. 2012;7:e50222.

17. Beltrami AP, Cesselli D, Bergamin N, et al. Multipotent cells can be generated in vitro from several adult human organs (heart, liver, and bone marrow). Blood. 2007;110:3438-46.

18. Zhang Q, Shi S, Liu Y, et al. Mesenchymal stem cells derived from human gingiva are capable of immunomodulatory functions and ameliorate inflammation-related tissue destruction in experimental colitis. J Immunol. 2009;183:7787-98.

19. Rosland GV, Svendsen A, Torsvik A, et al. Long-term cultures of bone marrow-derived human mesenchymal stem cells frequently undergo spontaneous malignant transformation. Cancer Res. 2009;69:5331-9.

20. Xu QL, Shanti RM, Zhang QZ, et al. A gingiva-derived mesenchymal stem cell-laden porcine small intestinal submucosa extracellular matrix construct promotes Myomucosal regeneration of the tongue. Tissue Eng Pt A. 2017; 23:301-12.

21. Su WR, Zhang QZ, Shi SH, et al. Human gingiva-derived mesenchymal stromal cells attenuate contact hypersensitivity via prostaglandin E2dependent mechanisms. Stem Cells. 2011;29:1849-60.

22. Zhang QZ, Su WR, Shi SH, et al. Human gingiva-derived mesenchymal stem cells elicit polarization of $\mathrm{m} 2$ macrophages and enhance cutaneous wound healing. Stem Cells. 2010;28:1856-68.

23. Huang F, Chen M, Chen W, et al. Human gingiva-derived mesenchymal stem cells inhibit xeno-graft-versus-host disease via CD39-CD73-adenosine and IDO signals. Front Immunol. 2017:8:68.

24. Huang F, Liu ZM, Zheng SG. Updates on GMSCs treatment for autoimmune diseases. Current Stem Cell Res Ther. 2018;3(5):345-9.

25. Poh KK, Sperry E, Young RG, et al. Repeated direct endomyocardial transplantation of allogeneic mesenchymal stem cells: safety of a high dose, "off-the-shelf", cellular cardiomyoplasty strategy. Int J Cardiol. 2007;117:360-4.

26. Furlani $D$, Ugurlucan $M$, Ong $L$, et al. Is the intravascular administration of mesenchymal stem cells safe? Mesenchymal stem cells and intravital microscopy. Microvasc Res. 2009;77:370-6.

27. Zhu W, Huang L, Li Y, et al. Mesenchymal stem cell-secreted soluble signaling molecules potentiate tumor growth. Cell Cycle. 2011;10:3198-207.

28. Redaelli S, Bentivegna A, Foudah D, et al. From cytogenomic to epigenomic profiles: monitoring the biologic behavior of in vitro cultured human bone marrow mesenchymal stem cells. Stem Cell Res Ther. 2012;3:47.

29. Verbeek R. Generation of mesenchymal stem cells as a medicinal product in organ transplantation. Curr Opin Organ Transplant. 2013;18:65-70.

30. Sun $L$, Xu R, Sun $X$, et al. Safety evaluation of exosomes derived from human umbilical cord mesenchymal stromal cell. Cytotherapy. 2016;18:413-22.

31. Gad SC, Sharp KL, Montgomery C, et al. Evaluation of the toxicity of intravenous delivery of auroshell particles (gold-silica nanoshells). Int J Toxicol. 2012;31:584-94.

32. Sampson HA, Munoz-Furlong A, Campbell RL, et al. Second symposium on the definition and management of anaphylaxis: summary report--second National Institute of Allergy and Infectious Disease/Food Allergy and Anaphylaxis Network symposium. Ann Emerg Med. 2006;47:373-80.

33. Goerge T, Ho-Tin-Noe B, Carbo C, et al. Inflammation induces hemorrhage in thrombocytopenia. Blood. 2008;111:4958-64.

34. Christensen AD, Haase $C$, Cook $A D$, et al. K/BxN serum-transfer arthritis as a model for human inflammatory arthritis. Front Immunol. 2016;7:213.
35. Xiu Xiao Z, Zheng X, Hu L, Wang J, Olsen N, Song Guo Zheng. Immunosuppressive effect of B7-H4 pathway in a murine systemic lupus erythematosus Model. Front Immunol. 2017:8:1765.

36. Maron DM, Ames BN. Revised methods for the Salmonella mutagenicity test. Mutat Res. 1983;113:173-215.

37. Molzer $\mathrm{C}$, Huber $\mathrm{H}$, Diem $\mathrm{K}$, et al. Extracellular and intracellular antimutagenic effects of bile pigments in the Salmonella typhimurium reverse mutation assay. Toxicol Vitro. 2013;27:433-7.

38. Lee MY, Seo CS, Kim JY, et al. Genotoxicity evaluation of Guibi-Tang extract using an in vitro bacterial reverse mutation assay, chromosome aberration assay, and in vivo micronucleus test. BMC Complement Altern Med. 2014;14:215.

39. Shin IS, Seo CS, Ha HK, et al. Genotoxicity assessment of Pyungwi-san (PWS), a traditional herbal prescription. J Ethnopharmacol. 2011;133:696-703.

40. Jin G, Matsushita T, Hamaguchi Y, et al. Basophils and mast cells play critical roles for leukocyte recruitment in lgE-mediated cutaneous reverse passive Arthus reaction. J Dermatol Sci. 2012;67:181-9.

41. Jung Y, Bauer G, Nolta JA. Concise review: induced pluripotent stem cellderived mesenchymal stem cells: progress toward safe clinical products. Stem Cells. 2012;30:42-7.

42. Samsonraj RM, Raghunath M, Nurcombe V, et al. Concise review: multifaceted characterization of human mesenchymal stem cells for use in regenerative medicine. Stem Cells Transl Med. 2017;6:2173-85.

43. von Tigerstrom B. Revising the regulation of stem cell-based therapies: critical assessment of potential models. Food Drug Law J. 2015;70:315-37 iii.

44. Fink DW Jr. FDA regulation of stem cell-based products. Science (New York, NY). 2009;324:1662-3.

45. Halme DG, Kessler DA. FDA regulation of stem-cell-based therapies. N Engl J Med. 2006;355:1730-5.

46. Sansone $V$, Branes M, Romeo P. A novel bimodal approach for treating atrophic bone non-unions with extracorporeal shockwaves and autologous mesenchymal stem cell transplant. Med Hypotheses. 2018;111:4-7.

47. Yamaoka E, Hiyama E, Sotomaru Y, et al. Neoplastic transformation by TERT in FGF-2-expanded human mesenchymal stem cells. Int J Oncol. 2011;39:5-11.

48. Yang $\mathrm{KQ}$, Liu $Y$, Huang $\mathrm{QH}$, et al. Bone marrow-derived mesenchymal stem cells induced by inflammatory cytokines produce angiogenetic factors and promote prostate cancer growth. BMC Cancer. 2017;17:878.

49. Zhang T, Lee YW, Rui YF, et al. Bone marrow-derived mesenchymal stem cells promote growth and angiogenesis of breast and prostate tumors. Stem Cell Res Ther. 2013:4:70.

50. Liu Y, Han ZP, Zhang SS, et al. Effects of inflammatory factors on mesenchymal stem cells and their role in the promotion of tumor angiogenesis in colon cancer. J Biol Chem. 2011;286:25007-15.

51. Tomar GB, Srivastava RK, Gupta N, et al. Human gingiva-derived mesenchymal stem cells are superior to bone marrow-derived mesenchymal stem cells for cell therapy in regenerative medicine. Biochem Biophys Res Commun. 2010;393:377-83.

52. Li Z, Hu X, Mao J, et al. Optimization of mesenchymal stem cells (MSCs) delivery dose and route in mice with acute liver injury by bioluminescence imaging. Mol Imaging Biol. 2015;17:185-94.

53. Barbash IM, Chouraqui $P$, Baron J, et al. Systemic delivery of bone marrowderived mesenchymal stem cells to the infarcted myocardium: feasibility, cell migration, and body distribution. Circulation. 2003;108:863-8.

54. Ruster B, Gottig S, Ludwig RJ, et al. Mesenchymal stem cells display coordinated rolling and adhesion behavior on endothelial cells. Blood. 2006; 108:3938-44.

\section{Ready to submit your research? Choose BMC and benefit from:}

- fast, convenient online submission

- thorough peer review by experienced researchers in your field

- rapid publication on acceptance

- support for research data, including large and complex data types

- gold Open Access which fosters wider collaboration and increased citations

- maximum visibility for your research: over $100 \mathrm{M}$ website views per year

At $\mathrm{BMC}$, research is always in progress.

Learn more biomedcentral.com/submissions 